\title{
The Somnogen Visual Training a New CBT to Fight Insomnia through Closed Eyes and fNIRS Neuroimaging
}

\author{
Pierre-Alain Grounauer ${ }^{1}$, Bastien Métraux ${ }^{2}$ \\ ${ }^{1}$ University Eye Clinic, Lausanne, Switzerland \\ ${ }^{2}$ Centre Hospitalier Universitaire Vaudois (CHUV), Lausanne, Switzerland \\ Email: pagrounauer@bluewin.ch
}

Received 6 August 2014; revised 22 September 2014; accepted 10 October 2014

Copyright @ 2014 by authors and Scientific Research Publishing Inc.

This work is licensed under the Creative Commons Attribution International License (CC BY). http://creativecommons.org/licenses/by/4.0/

(c) (i) Open Access

\begin{abstract}
The use of a red light observed through closed eyes is a new CBT Cognitive Behavioral Therapy to fight insomnia. Its principles are based on the high transmission of the colour red through eyelids, the great sensitivity to light of the retina when it is adjusted to darkness and the mental distraction obtained by the perception and attentive observation of variations of intensity. The prefrontal and occipital fNIRS recordings document this method which is correlated to the sleep EEG state II.
\end{abstract}

\section{Keywords}

Insomnia, CBT, Prefrontal-Occipital fNIRS, Sleep EEG State II, Mindfulness Meditations

\section{Introduction}

The primary function of the eye is to project simultaneous two different images onto both retinas while acting as the priority sensorial captor of the density of neuro-informations transmitted to the brain centers which are highly interconnected to ensure survival of the individual and the species. The continually supplied data adapt the position of the body to its environment and provides, in 3D, the stereotactic conditions for gripping and ensures the subtlety of predation. It also allows the early recognition of the maternal face and its emotional message [1]. The second function is to reset the brain clock daily by activating the retinal melanopsin-pineal gland channel to adapt the chrono-rhythm to vital social activities [2]. When this rhythm is altered and insomnia sets in, nocturnal vision, with eyes closed, becomes a powerful mental distraction capable of reducing the appearance of disturbing thoughts, their frequency and persistence. This third function, still relatively unknown, is possible 
thanks to the visual "giga-channel" which, with closed eyes, is always active and ready to transport visual informations, reduced here to a perception of red and black. This sensation then becomes a mental lever to lift the weight of insomnia.

\section{Method}

The aims of this pilot study are to present the objective and subjective psychophysical bases of Somnogen Visual Training SVT [3] useful for fighting insomnia which concerns almost $10 \%$ of the population. It should help prevent the use of certain potentially neurotoxic sleeping pills and avoid addiction only through the use of mental and physical resources [4]. The first objective data are the colored spectrum transmission curve through the eyelids [5] of which red is the best transmitted wavelength. Second the ERG recordings on the closed eye (Figure 1), adapted after 40 minutes in darkness. We observe that a very weak light $0.01 \mathrm{~cd}$ is sufficient to provoke an ERG response (Figure 2). Subjectively, we can observe that closed eyelids do not prevent the view of movement or the pink-colored perception of the sun. To avoid blocking the production of melatonin we must avoid a too-strong intensity, so we have chosen a minimal intensity of red which does not disturb the subject. The timing variations in the form of alternate red and black pulsations arouse the attention and maintain vigilance. This visual sensation diverts the attention and becomes a mental distraction which breaks the obsessive circle of insomnia.

\section{Material}

The fNIRS recordings come from a Shimadzu FOIRE 3000 infrared spectroscope recorded in a darkened silent room. Nine optodes are placed on the prefrontal and occipital cortices $2 \times 12$ channels (Figure 3). The subject
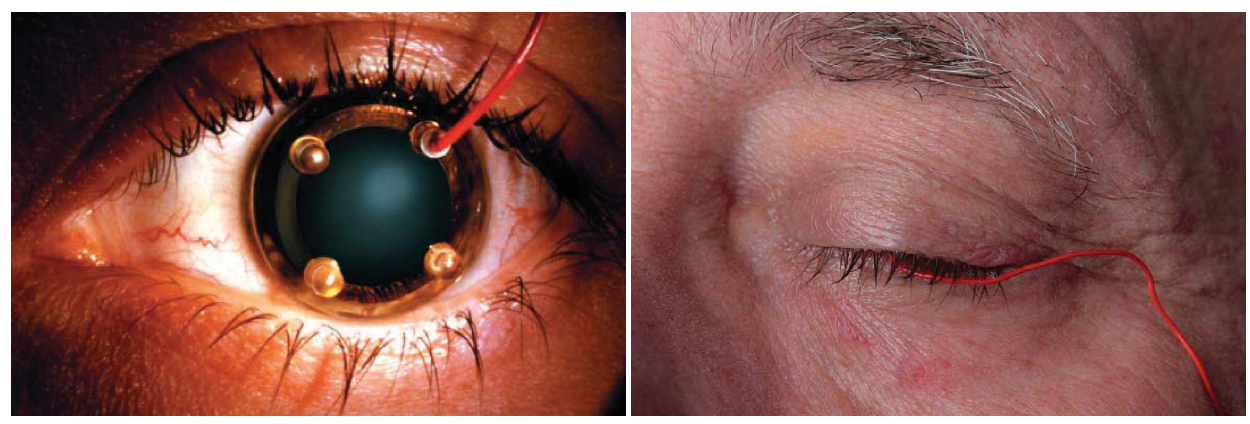

Figure 1. ERG recording with the ERG-jet corneal contact lens electrode. The left eye open, right eye closed. Three pillars have been cut off [6].

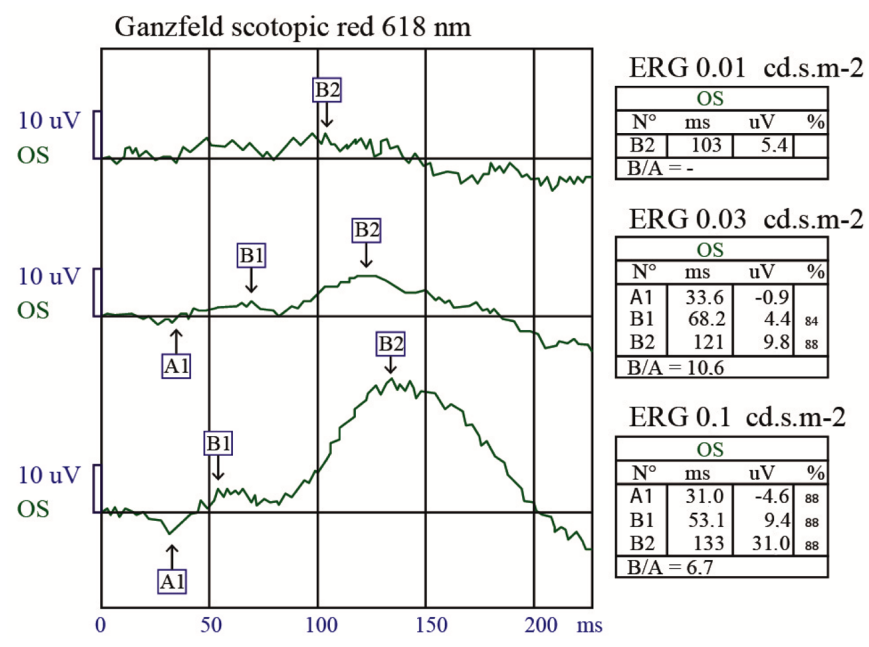

Figure 2. Dark adapted red ERG: 0.01 cd.s.m-2 stimulation light is already effective to obtain recordings [7]. 


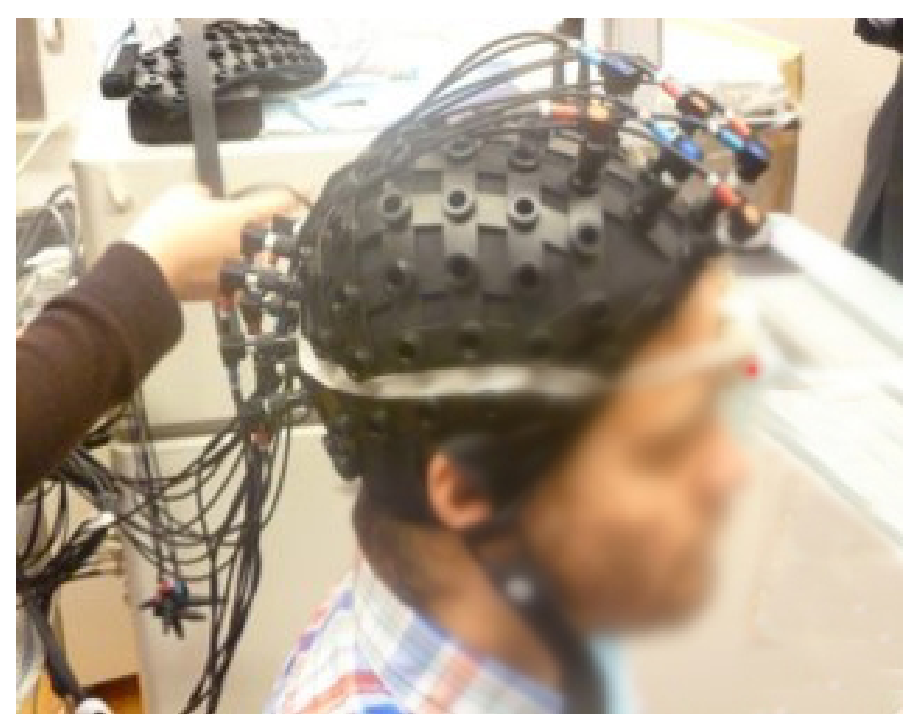

Figure 3. Nine prefrontal and 9 occipital optodes at sites. Between the two eyes the light mental distractor SLEAPI.

tested in a sitting position is 21 years old, right-handed and in good health, with no addictions or medication. He has never previously practised SVT. The stimulator SLEAPI [8] consists of a $625 \mathrm{~nm}-5$ mcd LED placed in the centre of the forehead. The sinusoidal stimulation lasts 6 seconds, followed by a black phase lasting 11 seconds. The recording lasted 120 seconds.

\section{Results}

Figure 4 shows after 120 seconds the oxy and deoxyhemoglobin asymmetric concentrations in prefrontal area. Interesting is the occipital visual cortex which is relatively silent.

\section{Discussion}

Concerning the ERG on the closed eye, our results have been repeated several times on several different people using different electroretinographs. There is no equivalent in literature. Concerning the fNIRS recordings, this technique is considered to be sufficiently sensitive and specific to be valid evidence of the neocortical hemodynamic variations [9] [10]. To date, it has not been applied to a similar task in a situation of minimal visual perception with closed eyes.

Our fNIRS results stand in the research of the geo-localization of intellectual activities and specifically the right and left functions of the prefrontal cortices [11]-[20]. If the frontal lobe is the preferred area for conceptual activities, opinions diverge on its asymmetric role [21] [22]. Note that in a situation of ostracism and social rejection, Peterson CK et al. [23] has shown a predominance of the left prefrontal cortex. However, our study shows a hemodynamic silence of this lobe. Should we conclude that visual training SVT allows these neurons to rest and therefore facilitates sleep induction? Is this the explanation? Note, too, that the occipital visual cortices are not aroused. This is surprising when we know that stimulation using a black and white checkerboard is the best way to obtain quality VEP visually evoked potentials. In this visual task which does not use formal vision, we must admit that these occipital neurons are resting and the essential part of the brain activity is prefrontal.

A second correlation could explain the psychophysiology of SVT by sleep EEG mapping state II (Figure 5) where frontal predominance is obvious [24].

Lastly, note that in order to increase the efficacy of SVT it is useful to associate the control of breathing and respiratory relaxation [25] together with a reduction in the muscle tonus of the lower limbs [26]. We should also note that the positioning of the red LED in the centre of the forehead is a position usually reserved for the 3rd eye, also called the serenity and diamond's, which is frequently seen on Buddhist statues. This is probably more than a methodological coincidence, possibly a hidden synergy which should not surprise those who practise meditations [27]-[30]. 


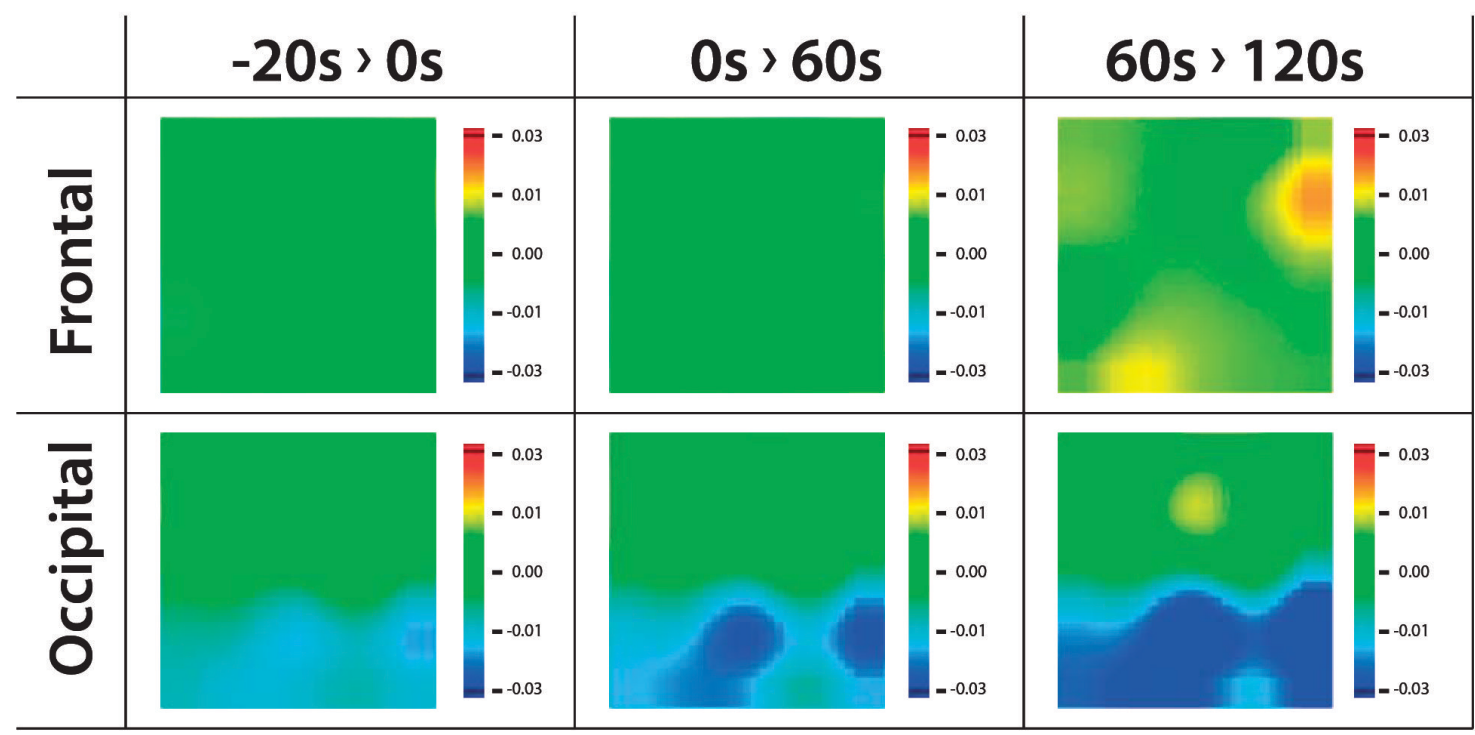

Before stimulation, no hemodynamic After 2 minutes stimulation, the hemodynamic precortical variations are variation is recordable strong and asymmetric and the cortical variations weaker

Figure 4. fNIRS mapping. The right prefrontal is clearly more active than the left one and there is fast no activity in occipital areas.

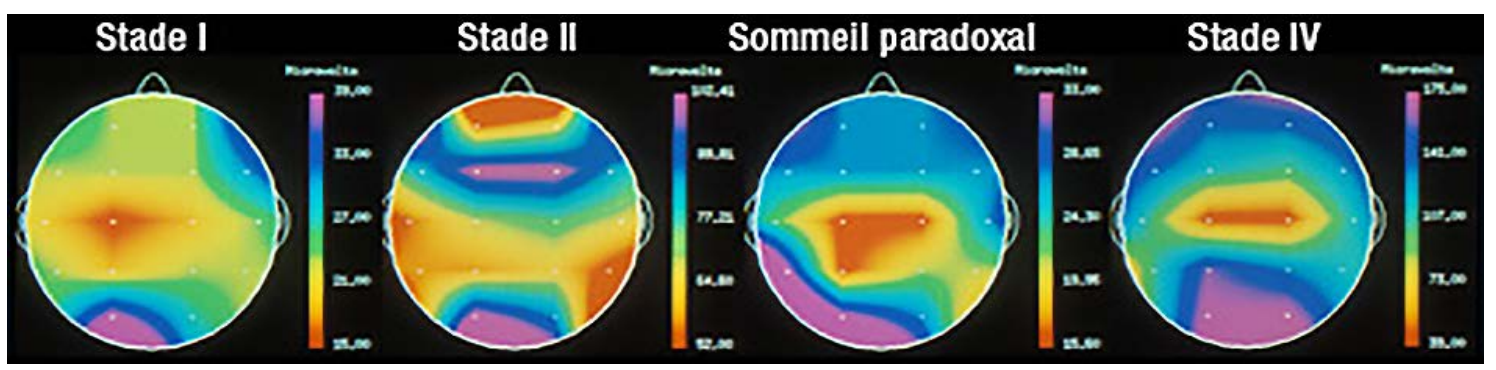

Figure 5. Sleep mapping EEG. State II shows a frontal prevalence activity [24].

\section{Conclusion}

This pilot study exposes the objective and subjective bases of a new CBT, proposes fNIRS recordings and establishes a correlation between them and stage II sleep illustrated by EEG. The use of a very weak red light allows it to be described as an intellectual distraction capable of fighting insomnia. In the field of CBT, it has never been described at time in the literature. It proposes to use its advantages and the simplicity of application encourages its daily use in order to control sleep disorders and addictions due to certain sleeping pills or thymoleptic drugs. Its innovative character is now awaiting statistical confirmation for verification and validation.

\section{Acknowledgements}

Prof. Niels Birbaumer, Prof. Vo Van Toi, Prof. Patrick Lemoine, Dr. Thierry Faivre, Prof. Claude Gronfier, Dr. Jean-François Millo, Prof. Michael Terman, Prof. H. Kokubo, Dr. François Choffat, Jacques et Nicky Fournier, Olivier Regenass, David Vigo, Roland Bays, Jean-Jacques Crausaz, Gaston Schaefer, Gérard Pons, Bénédicte Wildhaber, Bruno Cholat, Charles Houriet, Jacques Charlier, Martine Crochet, Eliette Christen, Michel Onfray, Dr. Bertrand Piccard, Prof. André Mazière, Prof. Dan Ciulin, Prof. Aki Kawasaki.

\section{References}

[1] Marendaz, C. (2009) Du regard à l'émotion: La vision, le cerveau, l'affectif. Les Essais du Pommier.

[2] Terman, M. and McMahan, I. (2012) Chronotherapy. Avery Penguin Group Inc., New York. 
[3] Grounauer, P.A. (2014) Sleaping Light Emission Awaking Provider Instrument. http://somnogenvt.ch

[4] Lemoine, P. (2014) Soigner sa tête sans medicaments ou presque. Robert Laffont.

[5] Bierman, A., Figueiro, G. and Rea, M.S. (2011) Measuring and Predicting Eyelid Spectral Transmittance. Journal of Biomedical Optics, 16, 067011. http://dx.doi.org/10.1117/1.3593151

[6] http://fabrinal.com

[7] http://metrovision.fr

[8] http://sleapi.ch

[9] Sitaram, R., Caria, A. and Birbaumer, N. (2009) Hemodynamic Brain-Computer Interfaces for Communication and Rehabilitation. Neural Networks, 22, 1320-1328. http://dx.doi.org/10.1016/j.neunet.2009.05.009

[10] Kokubo, H., Yamamoto, M., Katsurugawa, H., Kamada, A., Kawano, K., Hashizume and S., Watanabe, T. (2008) Research on Brain Blood Flow during Taichi-Quan by Using fNIRS. Journal of International Society of Life Information Science, 26, 134-137.

[11] Ernst, L.H., Plichta, M.M., Lutz, E., Zesewitz, A.K., Tupak, S.V., Dresler, T., Ehlis, A.C. and Fallgatter, A.J. (2013) Prefrontal Activation Patterns of Automatic and Regulated Approach-Avoidance Reactions-A Functional NearInfrared Spectroscopy (fNIRS) Study. Cortex, 49, 131-142.

[12] Barnhofer, T., Chittka, T., Nightingale, H., Visser, C. and Crane, C. (2010) State Effects of Two Forms of Meditation on Prefrontal EEG Asymmetry in Previously Depressed Individuals. Mindfulness, 1, 21-27. http://dx.doi.org/10.1007/s12671-010-0004-7

[13] Van Ha, D., et al. (2014) fNIRS-Based Wawelwt Thresholds for Motor Area Determination. BME5 Ho Chi Minh City Springer, in Press.

[14] Hoang, T., Tran, D., Truong, K., Nguyen, P., Vo Van, T., Huang, X. and Sharma, D. (2013) High Order Moment Features for NIRS-Based Classification Problems. IFMBE Proceedings, 40, 4-7.

[15] Hoang, T., Tran, D., Truong, K., Nguyen, P., Vo Van, T., Huang, X. and Sharma, D. (2013) Experiments on Synchronous Nonlinear Features for 2-Class NIRS-Based Motor Imagery Problem. IFMBE Proceedings, 40, 8-12.

[16] Le Giang, T., et al. (2014) Evaluation of Hemodynamic Responses to Visual Tasks Using Functional near Infrared Spectroscopy. BME5 Ho Chi Minh City Springer, in Press.

[17] Nhut Tuan, V., et al. (2014) Differentiation of Hemodynamic Responses of the Brain with Typing and Writing. BME5 Ho Chi Minh City Springer, in Press.

[18] Luong Nghia, H., Dang Khoa, T.Q., Tan, T.X., Duc Thien, D., Phuong Trinh, N.N. and Van Toi, V. (2013) Investigating Physiology of Untruth in Cerebral Cortex by Functional Near-Infrared Spectroscopy (fNIRS). IFMBE Proceedings, 40, 1-3. http://dx.doi.org/10.1007/978-3-642-32183-2 1

[19] Thanh Thao, P., et al. (2014) Evaluation of Frontal Visual Cortices on Mental Working Tasks Using Functional near Infrared Spectroscopy. BME5 Ho Chi Minh City Springer, in Press.

[20] Grounauer, P.A. (2014) A Pilot Study: The Somnogen Visual Training a New CBT to Fight Insomnia through Closed Eyes and fNIRS Neuroimaging. BME5 Ho Chi Minh City Springer, in Press.

[21] Herrington, J.D., Heller, W., Mohanty, A., Engels, A.S., Banich, M.T., Webb, A.G. and Miller, G.A. (2010) Localization of Asymmetric Brain Function in Emotion and Depression. Psychophysiology, 47, 442-454. http://dx.doi.org/10.1111/j.1469-8986.2009.00958.x

[22] Travis, F. and Arenander, A. (2004) EEG Asymmetry and Mindfulness Meditation. Letters to the Editor. Psychosomatic Medicine, 66, 147-152. http://dx.doi.org/10.1097/00006842-200401000-00020

[23] Peterson, C.K., Gravens, L.C. and Harmon-Jones, E. (2011) Asymmetric Frontal Cortical Activity and Negative Responses to Ostracism. Social, Cognitive, and Affective Neuroscience, 6, 227-285.

[24] http://inserm.fr/thematiques/neurosciences-sciences-cognitives-neurologie-psychiatrie/dossiers-d-information/sommeil

[25] Christen, E. (1996) Au centre du corps, le souffle. Edition LEP, Le Mont-sur-Lausanne.

[26] Schultz, J.H. (2005) Le Training Autogène. PUF, Paris.

[27] Mathieu, R. (2008) Lao tseu. Le Daode jing. Entrelacs 11, Paris.

[28] Ricard, M. (2010) L'art de la Méditation. Pocket Evolution. NIL Edition, Paris.

[29] Hanson, R. (2011) Buddha’s Brain. New Harbinger Publications, Oakland.

[30] Andre, C. (2011) Méditer, jour après jour. l’Iconoclaste, Paris. 
Scientific Research Publishing (SCIRP) is one of the largest Open Access journal publishers. It is currently publishing more than 200 open access, online, peer-reviewed journals covering a wide range of academic disciplines. SCIRP serves the worldwide academic communities and contributes to the progress and application of science with its publication.

Other selected journals from SCIRP are listed as below. Submit your manuscript to us via either submit@scirp.org or Online Submission Portal.
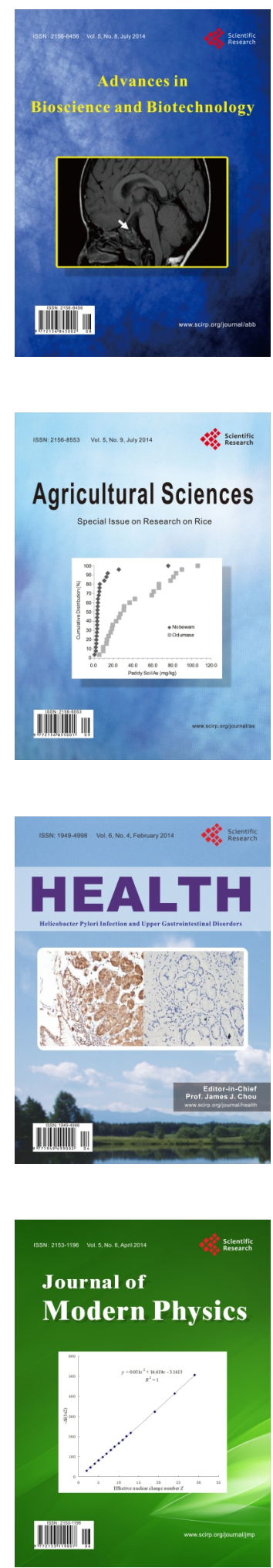
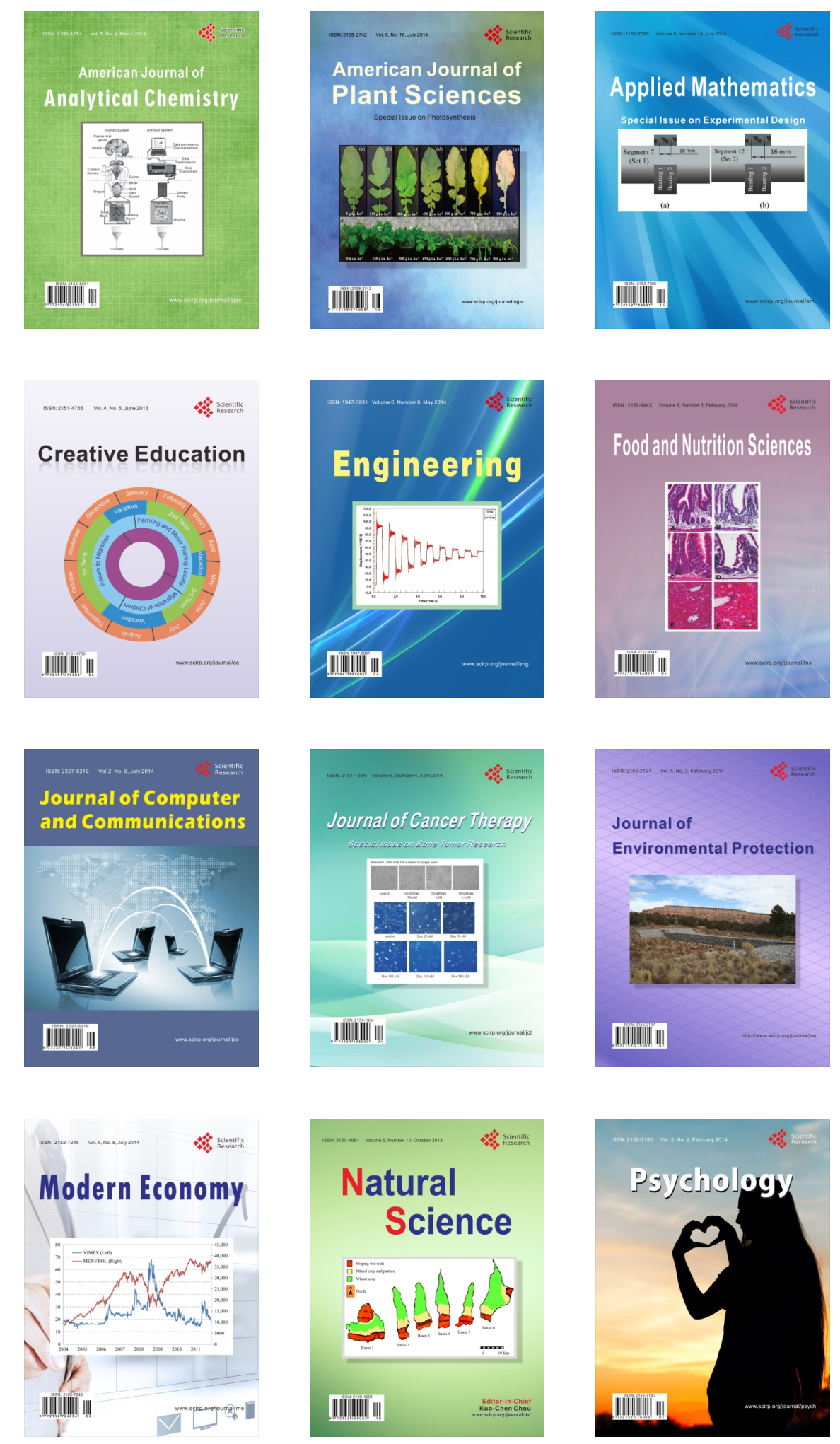